\title{
Computer Simulation Model of Single Stage Direct Control of Dc Machines Fed AC Voltage Source Using Single-Phase Matrix Converter (SPMC)
}

\author{
Nur Hidayah Abdullah, Rahimi Baharom, Muhammad Shawwal Mohamad Rawi and Mohd Shukri Mohd Ghazali
}

\begin{abstract}
This paper aims to present a new model of the singlestage direct control of DC machines fed with an AC voltage source using a Single-Phase Matrix Converter (SPMC). The proposed system uses a single circuit topology to perform four-quadrant control operations. Besides, enabling four quadrants control operation, the proposed circuit topology can be controlled to provide almost unity power factor operation using the supply current wave shaping technique. It features low power losses resulting in high power density. The theoretical model of the switching algorithms of the SPMC is utilized to control the desired output according to the characteristics of quadrant I, II, III, and IV operations. The simulation model of the proposed converter is developed using MATLAB/Simulink to investigate the circuit behaviors. The selected results are presented to verify the proposed converter.
\end{abstract}

Index Terms - Single-Phase Matrix Converter (SPMC), ACDC Converter and Active Power Filter (APF) Function.

\section{INTRODUCTION}

$\mathrm{T}$ HE power electronics community has heard for decades about the power electronics technological roadmap. Furthermore, a lower capital outlay in the building infrastructure and greater design freedom can be achieved with a small volume [1]. This is in line with the recent development of power electronic converters that are moving to the embedded in the final application. As a result, it can reduce the installation cost and enhance their electromagnetic compatibility [1]. The typical permanent magnet DC motor control uses two different converters (dual converter) as shown in Fig. 1 to perform four quadrants operation and requires additional devices for input

This manuscript is submitted on 23th January 2021 and accepted on 13th June 2021.This work was supported by the Reseach Management Centre (RMC) Universiti Teknologi MARA under Grant No: 600-RMC/LESTARI SDG-T 5/3 (188/2019).

Nur Hidayah Abdullah, Rahimi Baharom, Muhammad Shawwal Mohamad Rawi and Mohd Shukri Mohd Ghazali are with the School of Electrical Engineering, College of Engineering, Universiti Teknologi MARA, 40450 Shah Alam, Selangor (e-mail: hidayah0897@gmail.com, rahimi6579@gmail.com)

1985-5389/C 2021 The Authors. Published by UiTM Press. This is an open access article under the CC BY-NC-ND license (http://creativecommons.org /licenses/by-nc-nd/4.0/). current wave shaping to compensate the supply current to operate at almost unity power factor [1]. The use of separate converters circuit contributes to the increase of the number of semiconductor devices [2], which leads to the bulky size. Also, resulting in high power semiconductor losses and low power density [3-5]. Hence, this is not in line with the power electronic converter technological roadmap that focuses on reducing the power losses, size, and volume, thus, increase the power density [6] of the power converter system.

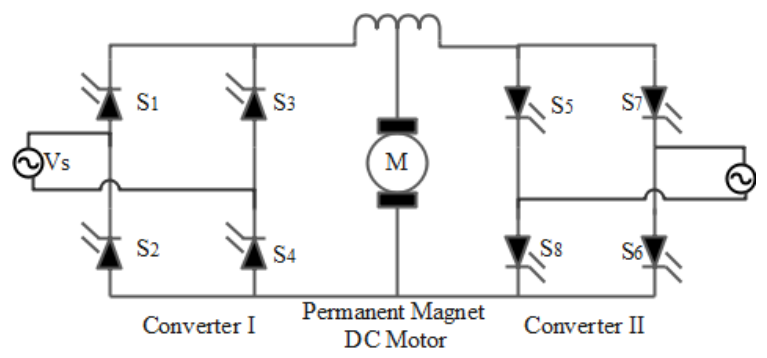

Fig. 1. Typical Dual Converter

This paper, therefore, proposes a single SPMC circuit topology to operate as a direct AC-AC converter to control four quadrants operation of a permanent magnet DC motor as shown in Fig. 2, which employs an Insulated-Gate Bipolar Transistor (IGBTs) for the main power switching devices [7]. Besides, the conversion of AC to DC, the SPMC circuit topology can also be used to uphold the supply current waveform of unity power factor operation through a proper switching arrangement [8-9]. The safe-commutation technique as presented in [10-12] is used to prevent the commutation problem due to the inductive load with regards to the voltage spikes during switch transitions. To verify the performance and viability of the proposed switching algorithms, a computer simulation model using MATLAB/Simulink is developed. 


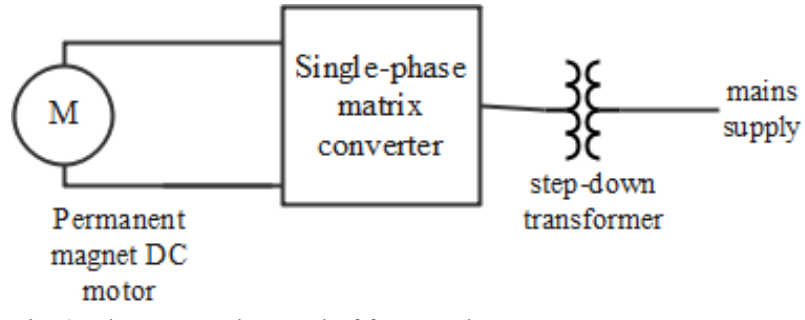

Fig. 2. The proposed control of four quadrant PMDC motor

\section{SINGLE-PHASE MATRIX CONVERTER (SPMC)}

Fig. 3 shows the SPMC circuit configuration. The SPMC has great potential in offering direct $\mathrm{AC}-\mathrm{AC}$ conversion without energy storage elements [13]. An important practical issue to consider with the application of matrix converters is the switching transitions problem [14]- [16]. Therefore, a systemic switching sequence is required to decay the energy flowing in the IGBTs. For this reason, freewheeling diodes are used in traditional-operated rectifiers. But, there is no need for this in SPMC so that a switching sequence can be established to allow energy dissipation.

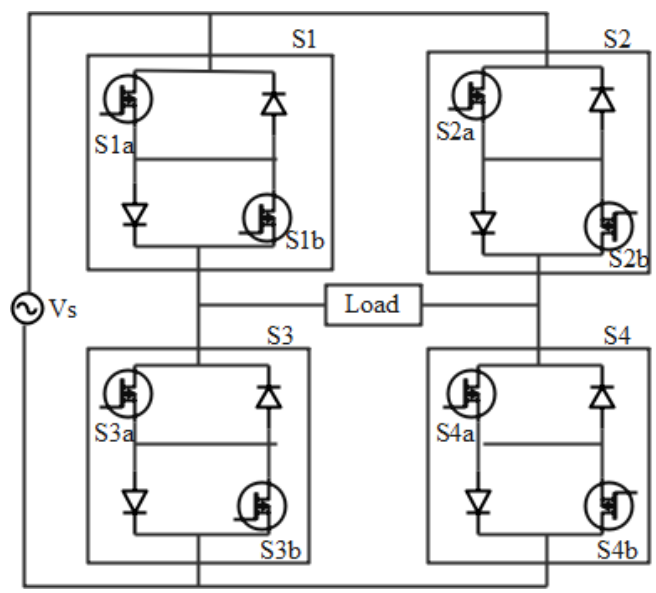

Fig. 3. SPMC circuit configuration

\section{The NeEd For High Power Density AC To DC CONVERTER To CONTROL OF Four QUadrant PERMANENT MAGNET DC MOTOR}

High efficiency and high power density of power supply are important for the rapidly changing global manufacturing environment. The current trend in power electronics is to increase the power density of conversion voltage, particularly for information technology applications in which the rapid development of integrated circuit technology had led to the higher power consumption of more compact systems [20]. Every 10 years since 1970, the power density of power electronic converters has almost doubled in various applications. Lower capital expenditure on the construction infrastructure and greater flexibility of design can be achieved with a small volume. This is consistent with the recent development of power electronic converters and drive systems which move to the integrated part of the final application [21][22]. The Matrix Converter (MC) is an emerging converter and currently has a significant interest in both academic and commercial matters [23]. The probability of higher power density due to a shortage of a DC link [24] in direct AC conversion is one of the major advantages claimed for the MC. Moreover, MC can function in all four quadrants operations. These characteristics make the $\mathrm{MC}$ a great alternative to the conventional inverter voltage source [25].

\section{THE Proposed AC TO DC CONVERTER For CONTROL OF Four QuADRANT PERMANENT MAGNET DC MOTOR}

A new AC to DC converter for control of four quadrants permanent magnet DC motor is developed using the SPMC circuit topology. The SPMC will perform the dual converter operation of the conventional circuit topology. By suitable control, the added features could be implemented in the form of supply-side unity power factor operation, active filter, and reactive compensation [26]. The limitation of the typical DC chopper circuit to control the four-quadrant operation of DC machines could also be solved using the proposed converter without any additional circuits [27]. The proposed system features low power losses resulting in high power density. The switching operations of the SPMC for the AC-DC conversion are only appropriate for the unidirectional flow of the current through the load in a time, both in the positive and negative cycles as shown in Fig. 4 [28]. The operations for quadrants II and IV are carried out with AC sources, and DC voltage sources are performed as an induced voltage at load side instead of inductor for easier simulation convergence [29]. The input frequency of the power supply is set to $50 \mathrm{~Hz}$. Four quadrant operations based on voltage and current profiles for quadrant I, quadrant II, quadrant III, and quadrant IV respectively is shown in Figs. 4 as stated in Table1. Both torque and speed characteristics for quadrants I and III move in the same forward and opposite direction respectively. Thus, quadrant I operate as forward motoring, and quadrant III is reverse motoring. As for quadrant II and IV, either speed or torque is moving in the opposite direction in each quadrant and causes the torque produced by the motor to 'brake' the speed rotation of the motor.

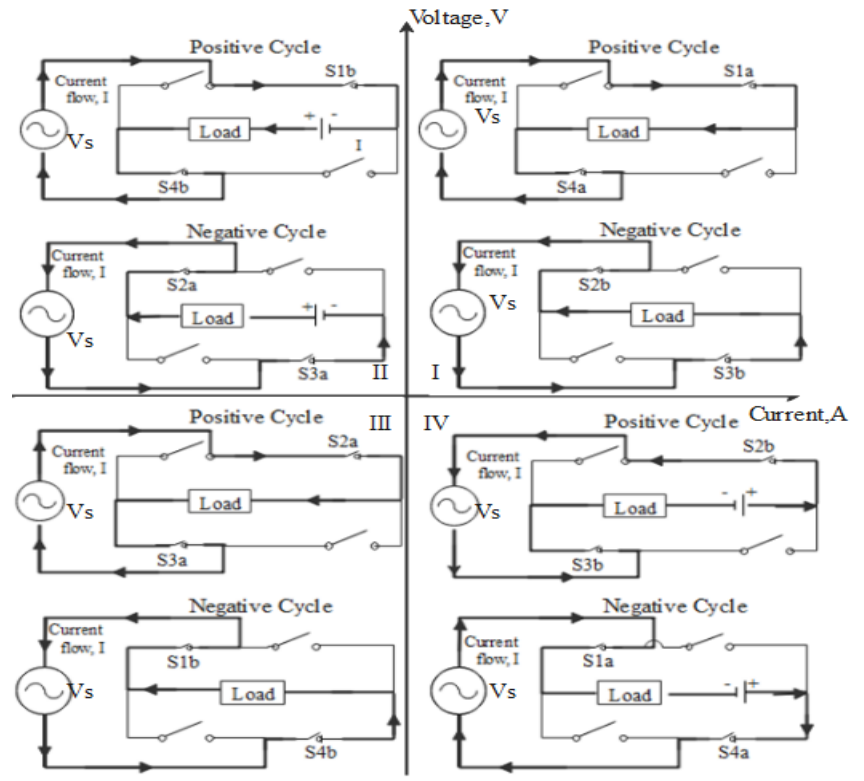

Fig. 4. Schematic circuit for the operation of four quadrants control 
TABLE I

SWITCHING ALGORITHMS OF FOUR QUADRANTS OPERATIONS

\begin{tabular}{llll}
\hline \hline Quadrants & $\begin{array}{c}\text { Positive } \\
\text { Cycle }\end{array}$ & $\begin{array}{c}\text { Negative } \\
\text { Cycle }\end{array}$ & Operations \\
\hline 1 & S1a, S4a & S3b, S2b & Forward Motoring \\
2 & S1b, S2b & S3a, S2b & Forward Braking \\
3 & S2a, S3a & S4b, S1b & Reverse Motoring \\
4 & S2b, S3b & S4a, S1a & Reverse Braking \\
\hline \hline
\end{tabular}

\section{COMPUTER SIMULATION}

The proposed converter has been investigated using MATLAB/Simulink (MLS) in terms of circuit operation for controlling of four quadrants operation of a DC motor as shown in Fig. 5 to Fig. 13. The SPMC is modeled using eight reverseblocking IGBTs, which have been connected to the commonemitter configuration by the combination of the two IGBTs and two power diodes as shown in Figs. 5 and 6 respectively. The control block set is designed to control the SPMC. It consists of the PWM generator as shown in Fig. 7, and the phase detector circuit to detect the phase sequence of $\mathrm{AC}$ voltage waveform as shown in Fig. 8. The SPMC circuit model with APF function is as shown in Fig. 9. The additional circuit of the Current Control Loop (CCL) is used to generate an Active Pulse Width Modulation (APWM) signal to control the SPMC circuit topology. An AC voltage source of $100 \mathrm{~V}$ (p-p) has been used to supply the proposed regulated rectifier operation. The investigations of the behavior of the proposed converter involving the use of inductive (RL) load as shown in Fig. 10 with the suitable safe-commutation strategy to solve the commutation problem in SPMC circuit topology. The simulation model of the SPMC circuit integrated with the active power filter (APF) function is shown in Fig. 11. The capacitive load with the resistor, R of $300 \Omega$ and DC capacitor filter of $1000 \mu \mathrm{F}$ are used with the switching frequency of $50 \mathrm{kHz}$. Further investigations are carried out with the advanced SPMC circuit topology to control four quadrants of DC machines operation as shown in Figs. 12 and 13.

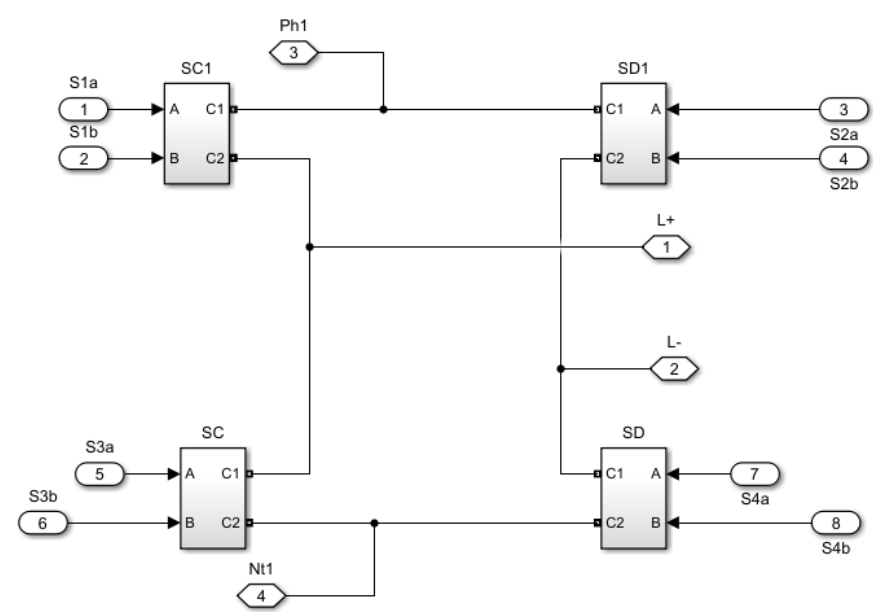

Fig. 5. The SPMC circuit model
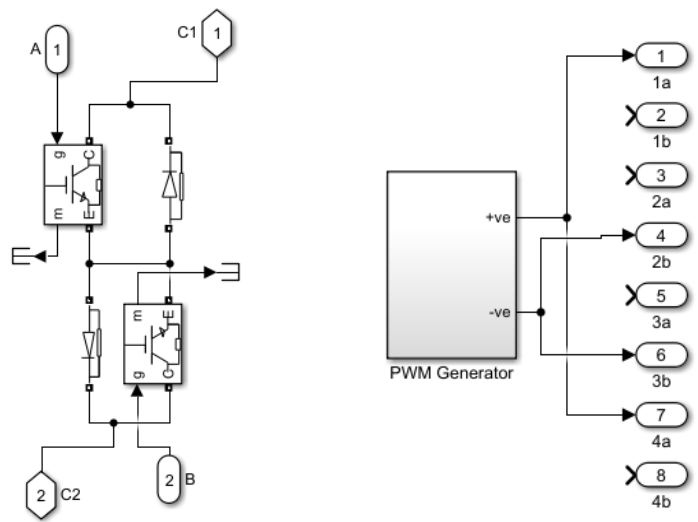

Fig. 6. Bidirectional Switch Model

Fig. 7. PWM Generator using MLS

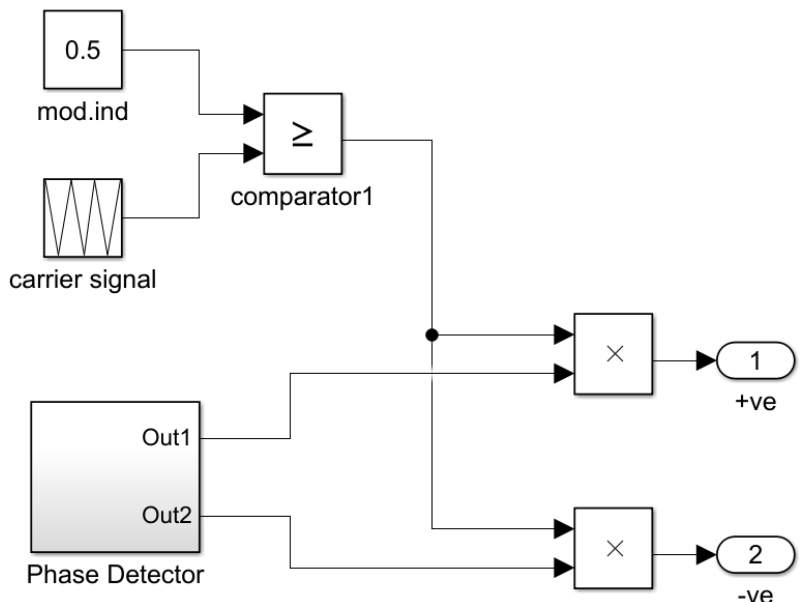

Fig. 8. Controller Circuit using MLS

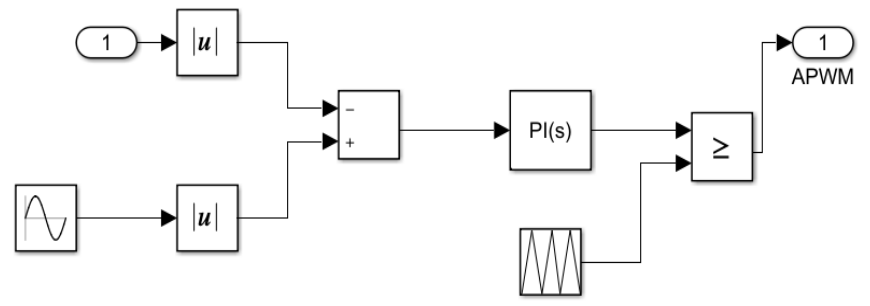

Fig. 9. Current controller

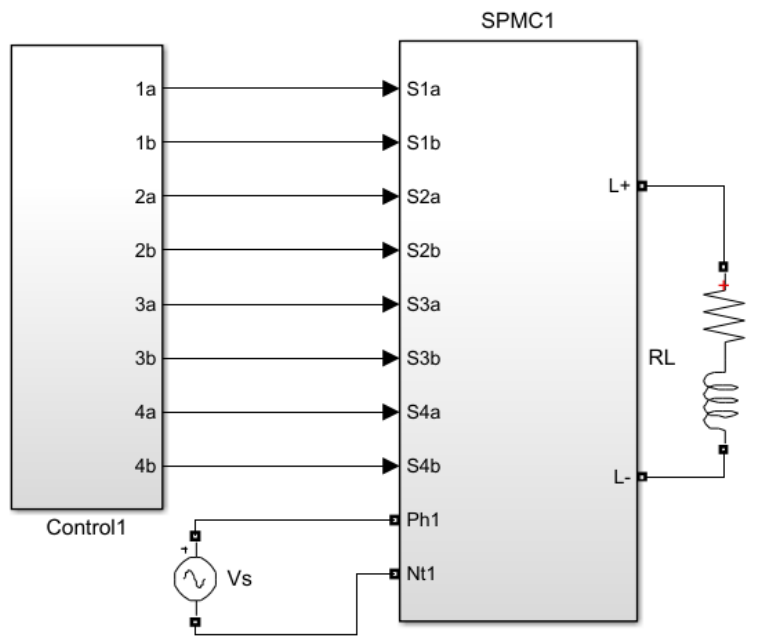

Fig. 10. SPMC with inductive (RL) loads 


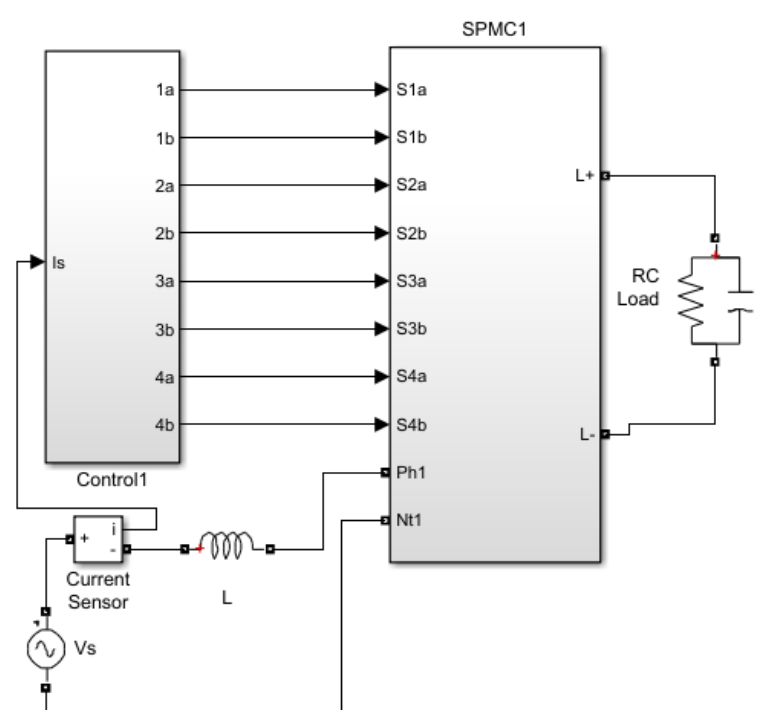

Fig. 11. SPMC incorporating with Active Power Filter (APF)

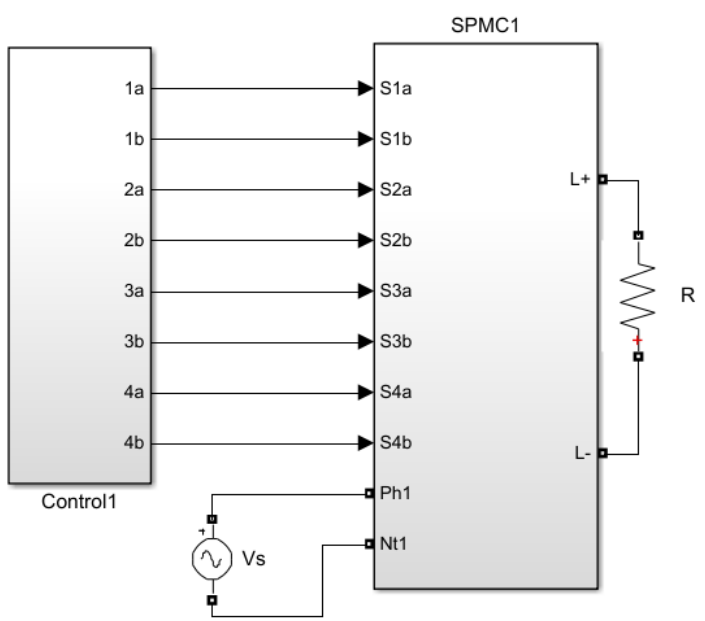

Fig. 12. SPMC with R Load for Quadrant I and III

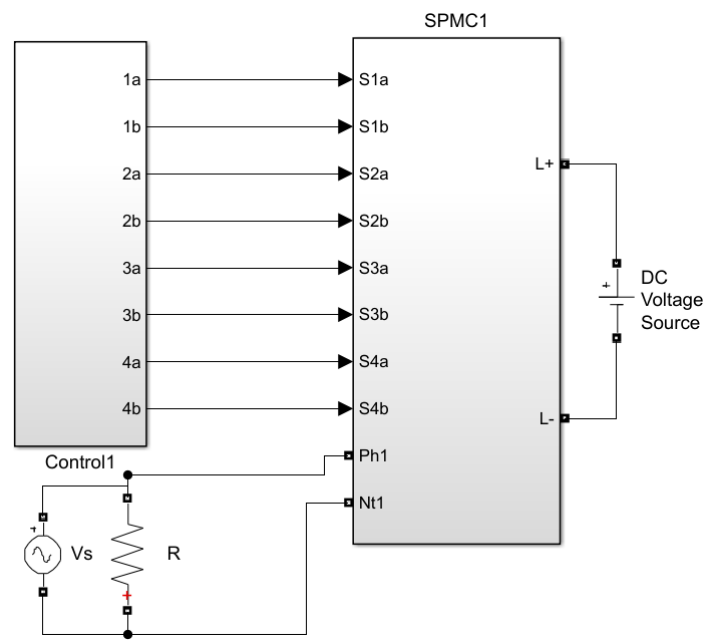

Fig. 13. SPMC with R Load for Quadrant II and IV

\section{RESULTS AND DISCUSSION}

Figs. 14 to 18 show the results obtained for the operation of SPMC as a controlled rectifier including the effect of inductive load and the safe-commutation strategy. Fig. 14 shows the results of the output voltage and current waveforms of a controlled AC-DC converter using a purely resistive load. Damaging spikes were observed with the presence of inductive load as shown in Fig. 15. The implementation of the safecommutations strategy led to the removal of voltage spikes as shown in Fig. 16. This result can be used to prove that the proposed safe-commutation technique is effective. The nonsinusoidal supply current waveform of the non-linear load is shown in Fig. 17. The inclusion of the APF function indicates that the supply current waveform is significantly improved, where the waveform becomes continuous, sinusoidal, and in phase with the supply voltage waveform as shown in Fig. 18.

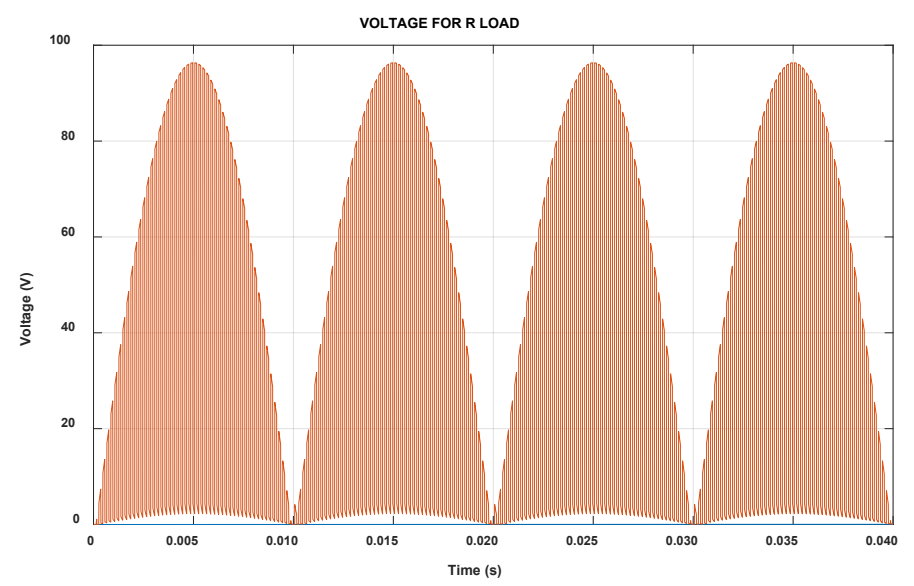

Fig. 14. Output voltage of R load from MLS

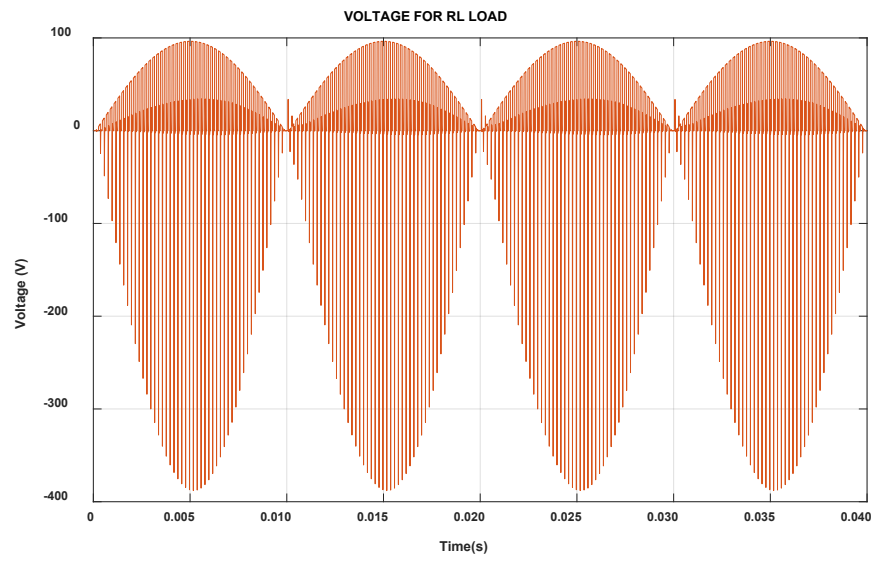

Fig. 15. Output voltage of RL load without commutation 


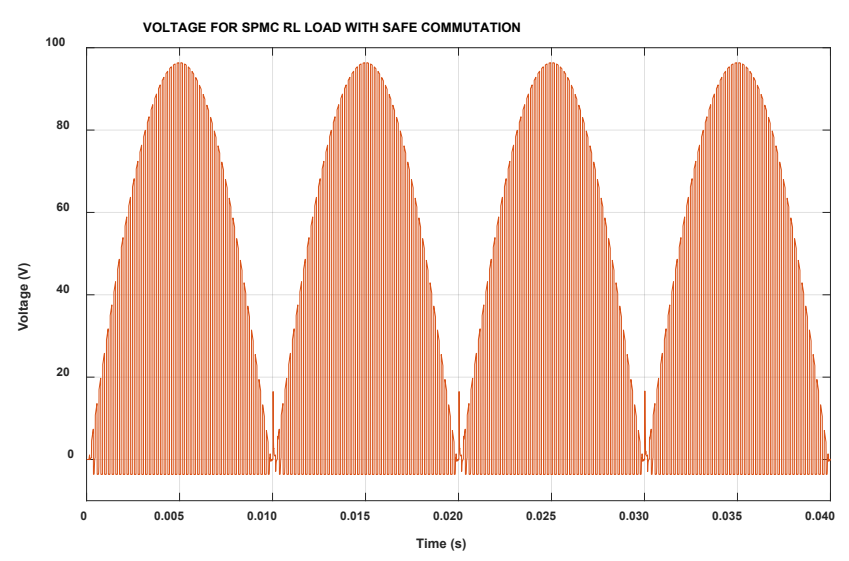

Fig. 16. Output voltage for RL load with safe commutation

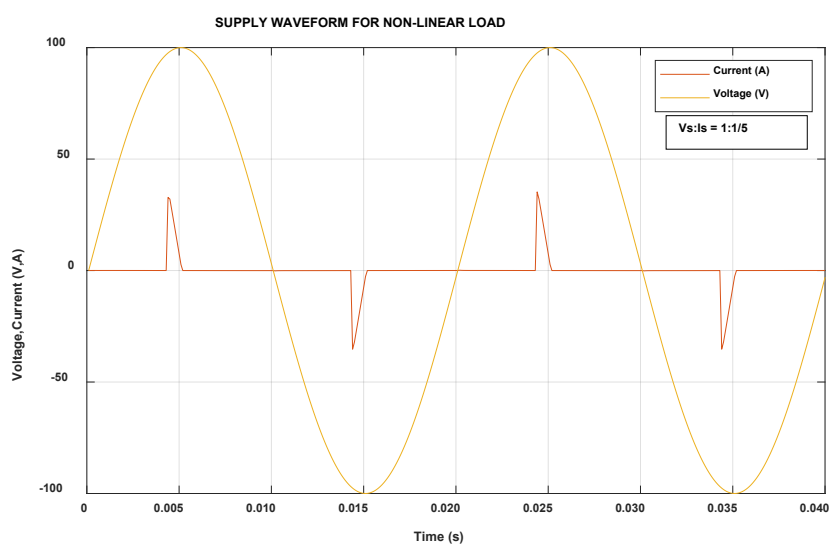

Fig. 17. Rectifier input signal of RL load without APF

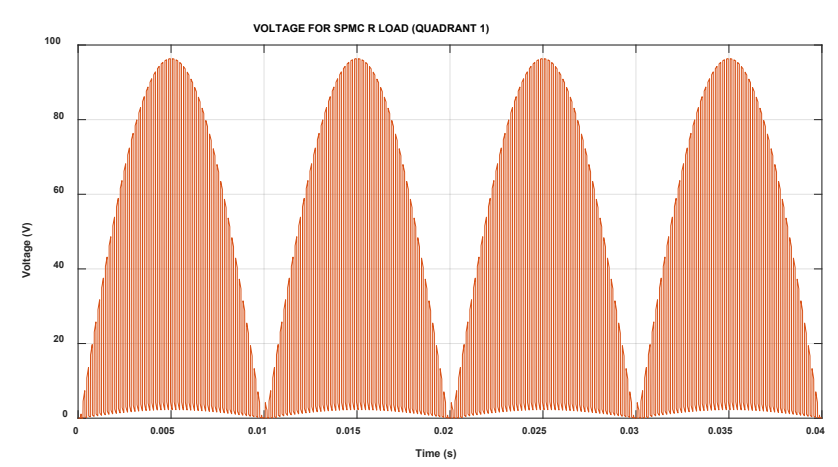

(a)

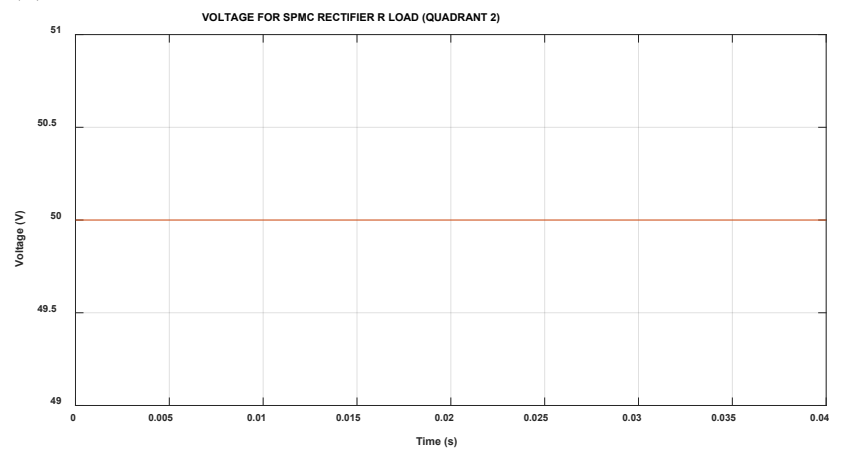

(c)

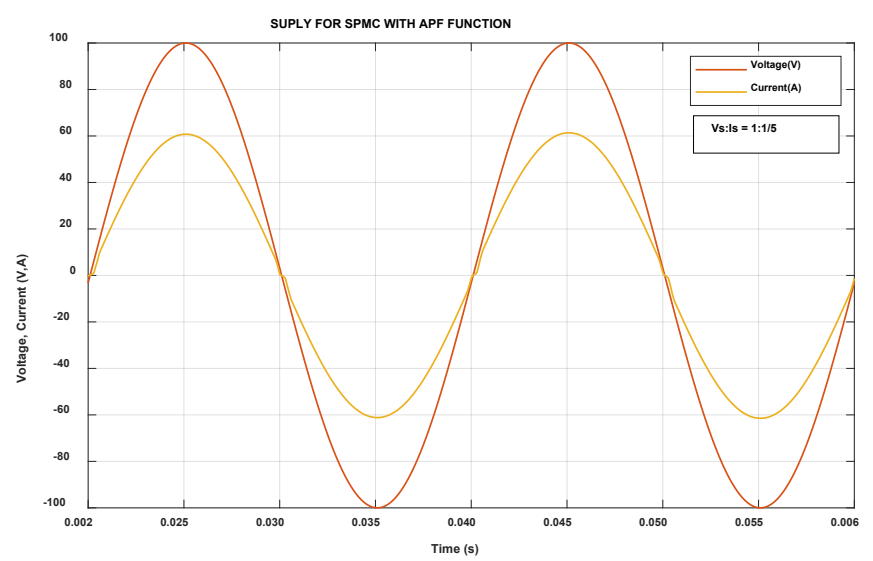

Fig. 18. Rectifier input signal of RL load with APF

Fig. 19 shows the results of four-quadrant operations of the DC drive system. Figs. 19 (a) and 19 (b) indicate the output voltage and current waveforms for Quadrant I operation. Both positive values of voltage and current waveforms verify the forward motor operation of the DC drive. Figs. 19 (c) and 19 (d) show the output voltage and current waveforms for Quadrant II operation where the voltage waveform is positive while the current waveform is negative. Figs. 19 (e) and 19 (f) demonstrate both voltage and current waveforms for Quadrant III operation. For Quadrant III operation, both output voltage and current waveforms are negative values, thus, verify the operation of the DC machine in the reverse motoring mode. Figs. 19 (g) and 19 (h) show the results for the Quadrant IV operation, where the current waveform is positive, and the voltage waveform is negative. The voltage and current profile for Quadrant IV verify the operation of the DC machine to operate in the reverse braking mode.

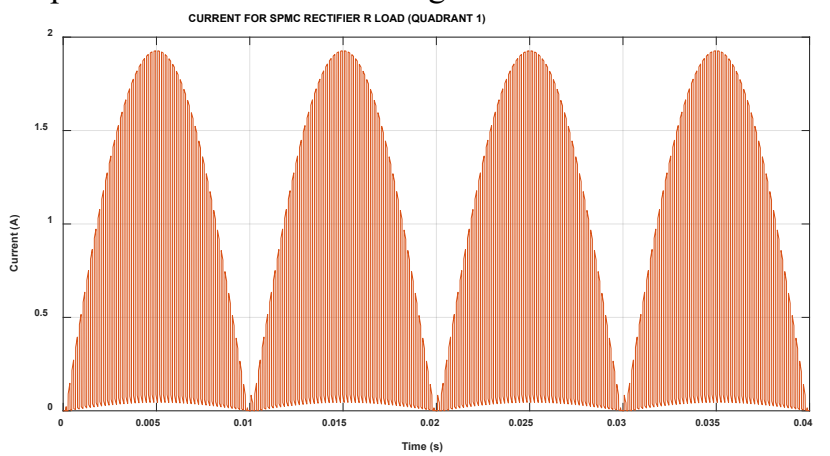

(b)

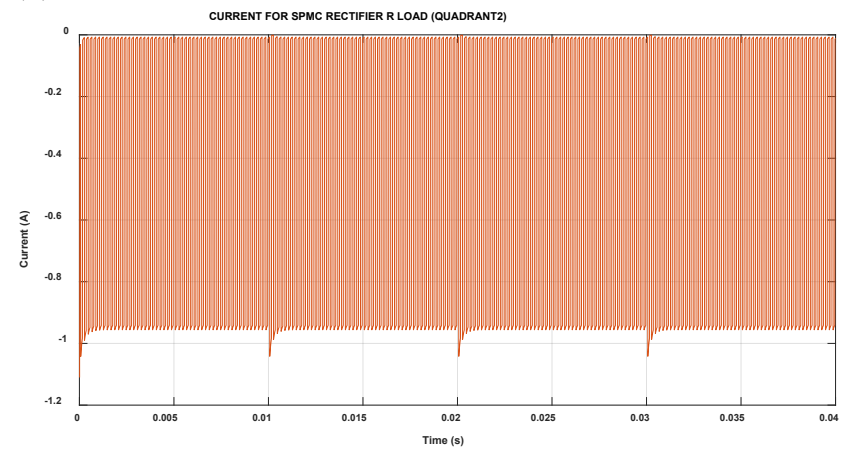

(d) 


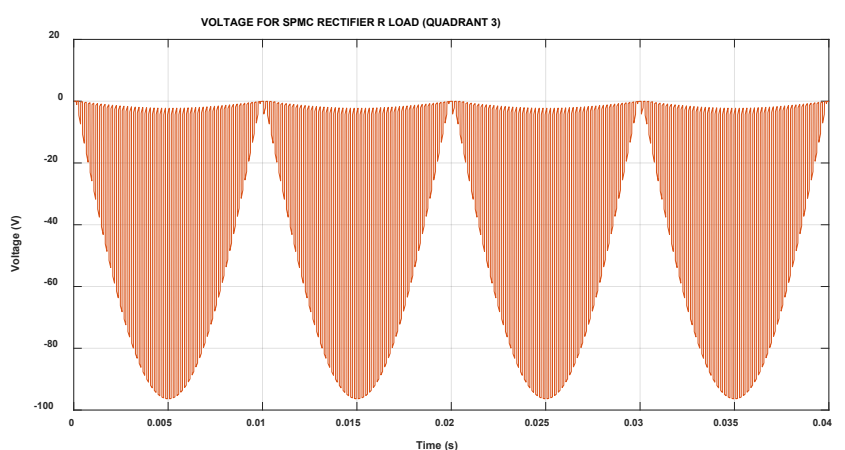

(e)

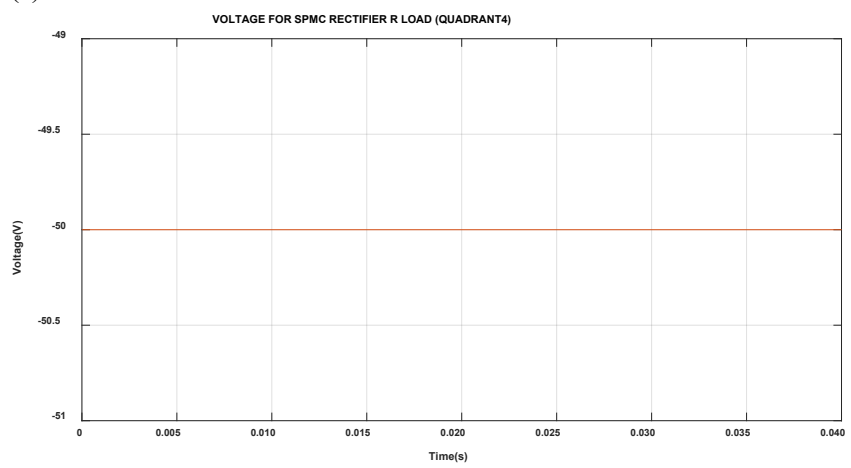

(g)

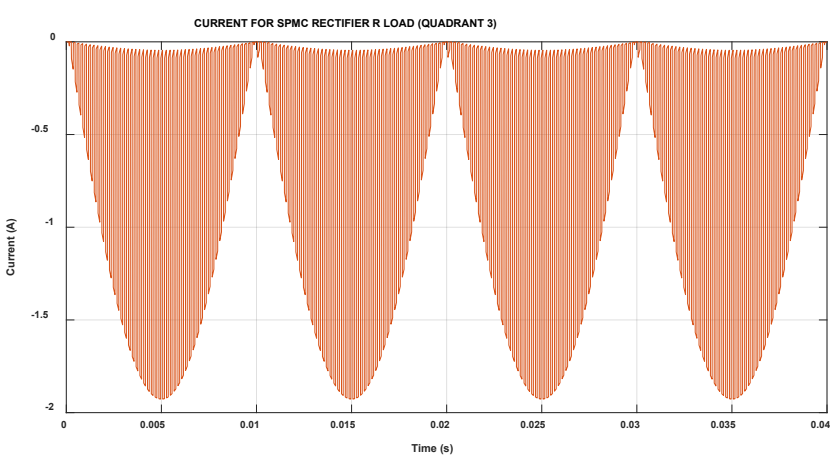

(f)

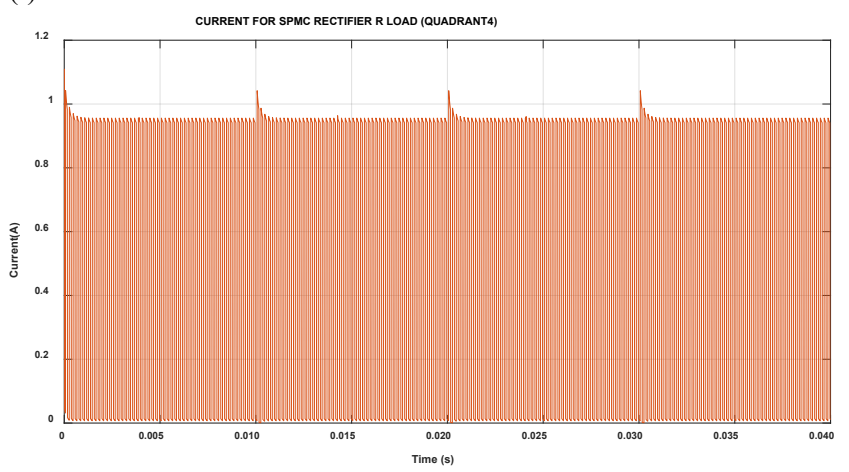

(h)

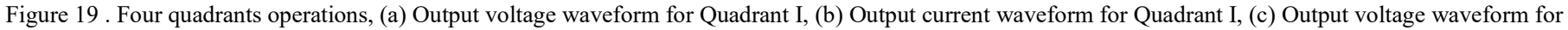

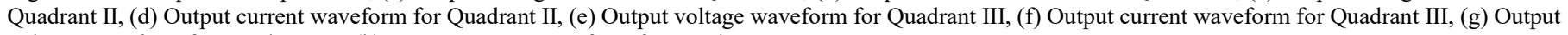
voltage waveform for Quadrant IV, (h) Output current waveform for Quadrant IV

\section{CONCLUSION}

The proposed new model of the AC-DC converter to control all four quadrant operations of the PMDC motor system has been presented. The limitation of the typical circuit topology to control four quadrant operations of the DC motor can be solved resulting in improving the power density of the electrical power converters. Despite improving the power density, the proposed system also has the capability to maintain a unity power factor operation of the supply current waveform by integrating with the APF function. Inherent commutation problems that lead to switching spikes are also investigated with a suitable safecommutation algorithm. As a result, such new enhancements can be used as a good foundation of future power electronic converters systems. Therefore, it could be expected that the developed AC-DC converter for control the four quadrants of the PMDC motor system with compact and high power density could help to minimize losses due to the multiple power conversion stages of the conventional power converters.

\section{ACKNOWLEDGEMENT}

Financial support from Reseach Management Centre (RMC) Universiti Teknologi MARA Grant No: 600-RMC/LESTARI SDG-T 5/3 (188/2019) is gratefully acknowledged.

\section{REFERENCES}

[1] R. Baharom, M. K. Hamzah, A. Saparon, S. Z. Mohammad Noor, and N. R. Hamzah, "A new single-phase controlled rectifier using single-phase matrix converter with regenerative capabilities,", 2007 7th International Conference on Power Electronics and Drive Systems, Year: 2007.

[2] S. Firdaus and M. K. Hamzah, "Modelling and simulation of a singlephase AC-AC matrix converter using SPWM," 2002 Student Conference on Research and Development: doi: 10.1109/SCORED.2002.1033113.

[3] A. Bindra, "Combining Motors and Drives Into Integrated Units [From the Editor]," IEEE Power Electron. Mag., vol. 7, no. 3, pp. 4-6, 2020, doi: 10.1109/mpel.2020.3011091.

[4] R. C. Becerra, T. M. Jahns and M. Ehsani; "Four-quadrant sensorless brushless ECM drive," Sixth Annual Applied Power Electronics Conference and Exhibition, 1991, pp. 202-209, doi: 10.1109/APEC.1991.146165.

[5] A. R. Daniels and D. T. Slattery, "New power convertor technique employing power transistors," Proc. Inst. Electr. Eng., vol. 125, no. 2, p. 146, 1978, doi: 10.1049/piee.1978.0038.

[6] S. Y. Liu and D. Zhang, "Research on brushless DC motor control system for electric vehicle," Advanced Materials Research, vol. 850- 851. pp. 661-664, 2014, doi: 10.4028/www.scientific.net/AMR.850-851.661.

[7] A. M. Ajmal and V. K. Ramachandaramurthy, "Regenerative Braking of Electric Vehicle with Brushless DC Motor," Applied Mechanics and Materials, vol. 785 . pp. 280-284, 2015, doi: 10.4028 /www.scientific.net/amm. 785. 28.

[8] A. Idris, R. Baharom, N. R. Hamzah, and M. K. Hamzah, "Controlled ACDC converter fed permanent magnet DC motor using single-phase matrix converter," Proc. 2013 IEEE 7th Int. Power Eng. Optim. Conf. PEOCO, no. June, pp. 764- 769, 2013, doi: 10.1109/PEOCO.2013.6564649.

[9] R. Baharom, N. R. Hamzah, and M. K. Hamzah, "A new safecommutation technique for AC-DC converter operation using single- 
phase matrix converter," 2012 IEEE Int. Conf. Power Energy, no. December, pp. 298-302, 2012, doi: 10.1109/PECon.2012.6450226.

[10] R. Baharom and M. K. Hamzah, "Advanced single-phase AC-DC converter using single-phase matrix converter topology incorporating with active power filter function," in Proceedings of the International Conference on Power Electronics and Drive Systems. pp. 1477- 1482, 2007, doi: 10.1109/PEDS.2007.4487899

[11] S. Z. M. Noor, R. Baharom, M. K. Hamzah, and N. R. Hamzah, "Safecommutation strategy for controlled rectifier operation using singlephase matrix converter," Proceedings of the International Conference on Power Electronics and Drive Systems. pp. 1026-1029, 2009, doi: 10.1109/PEDS.2009.5385720.

[12] Bland, M.J., Wheeler, P.W., Clare, J.C., Empringham, L., "Comparison of Bi-directional Switch Components for Direct AC-AC Converters", 2004 IEEE $35^{\text {th }}$ Annual Power Electronics Specialists Conference, 2004. PESC 04. Vol. 4, 2004, Page(s): 2905-2909.

[13] de Oliveira Filho, M.E, Ruppert Filho, E., Quindere, K.E.B., Gazoli, J.R., "A Simple Current Control for Matrix Converter", $41^{\text {st }}$ IAS Annual Meeting. Conference Record of the 2006 IEEE Industry Applications Conference, 2006. Vol. 4, Oct. 2006, Page(s): 2090-2094.

[14] M. Z. Efendi, A. Rizal, A. Erzanuari, . S., and N. A. Windarko, "AC-DC PFC Converter Using Combination of Flyback Converter and Full-bridge DC-DC Converter," Emit. Int. J. Eng. Technol., vol. 2, no. 1, 2014, doi: 10.24003/emitter.v2i1.21.

[15] M. F. M. Zin et al., "Voltage Controlled Single Phase Matrix Converter with Low Harmonics and Boost Characteristic," J. Phys. Conf. Ser., vol. 1529, no. 2, 2020, doi: 10.1088/1742- 6596/1529/2/0220552010 IEEE International Energy Conference, Dec. 2010, pp. 108-113

[16] R. Dhivya, V. J. Sudhakar, and R. Thilepa, "Single Phase Matrix Converter as a Frequency Changer with Sinusoidal Pulse Width Modulation using Matlab," vol. 4, no. 2, pp. 135-143, 2011, doi: 10.1109/ENERGYCON.2010.5771657.

[17] P. Deivasundari and V. Jamuna, "Single Phase Matrix Converter as an "All Silicon Solution," in 2011 1st International Conference on Electrical Energy Systems, ICEES 2011, Jan. 2011, pp. 86-91, doi: 10.1109/ICEES.2011.5725308.

[18] M. K. Hamzah, S. Z. M. Noor, and S. F. A. Shukor, "A new single-phase inverter using single-phase matrix converter topology," First International Power and Energy Conference, (PECon 2006) Proceedings. pp. 459-464, 2006, doi: 10.1109/PECON.2006.346695.

[19] Z. Idris, M. K. Hamzah, and M. F. Saidon, "Implementation of singlephase matrix converter as a direct AC-AC converter with commutation strategies," PESC Rec. - IEEE Annu. Power Electron. Spec. Conf., 2006, doi: 10.1109/PESC.2006.1712106.

[20] M. Welsh, P. Mehta, and M. K. Darwish, "Genetic algorithm and extended analysis optimisation techniques for switched capacitor active filters - Comparative study," IEE Proc. Electr. Power Appl., vol. 147, no. 1, pp. 21-25, 2000, doi: 10.1049/ip-epa:20000006.

[21] S. Vadhiraj, K. N. Swamy, and B. P. Divakar, "Generic SPWM technique for multilevel inverter," in Asia-Pacific Power and Energy Engineering Conference, APPEEC, Dec. 2013, pp. 1-5, doi: 10.1109/APPEEC.2013.6837117. active filters - Comparative study," IEE Proc. Electr.

[22] E. Bostanci, M. Moallem, A. Parsapour, and B. Fahimi, "Opportunities and Challenges of Switched Reluctance Motor Drives for Electric Propulsion: A Comparative Study," IEEE Transactions on Transportation Electrification, vol. 3, no. 1. pp. 58-75, 2017, doi: 10.1109/TTE.2017.2649883.

[23] Axelrod, Y. Berkovich, A. Ioinovici; Four-quadrant bi-directional drive system based on PWM DC-DC converter, 2008 10th IEEE International Workshop on Advanced Motion Control, Year: 2008.

[24] N. Vasquez, C. Aquilar, R. O. Caceres, I. Barbi and J. A. Gallegos, “A Novel Uninterruptible Power Supply System with Active Power Factor Correction," IEEE Transaction on Power Electronics, Vol. 17, No. 3, May 2002

[25] Steven Abaray, Stan Beaver, Chuong Nguyen, "How Reliable Is Your Uninterruptible Power System?: Eliminating Single Points of Failure, IEEE Industry Applications Magazine, Year: 2019, Vol. 25, Issue. 4.

[26] F. V. P. Robinson, "Power electronics converters, applications and design," Microelectronics Journal, vol. 28, no. 1. pp. 105-106, 1997, doi: 10.1016/s0026-2692(97)87859-7.

[27] G. N. Surya and S. Dutt, "A Simplified Switch Modulation Strategy for Matrix Converter," vol. 1, no. 3, pp. 160-165, 2012, [Online]. Available: https://www.ijeit.com/vol 1/Issue 3/IJEIT1412201203_34.pdf.
[28] H. M. George and R. Rajagopal, "Direct AC-AC Z-Source Matrix Converter for Single Phase Induction Motor," pp. 96-100, 2014. 2nd National Conference on Emerging Trends in Engineering - NET 2014. ISBN 978-93-83459-67-4 (c) 2014 Bonfring.

[29] A. N. Arvindan and V. K. Sharma, "Leading and lagging power factor operations of a four-quadrant AC-DC converter with sinusoidal line currents," Proc. IEEE Int. Conf. Ind. Technol., pp. 2142-2147, 2006, doi: 10.1109/ICIT.2006.3725 